\title{
Promoting Breast Cancer Screening Among Chamorro Women in Southern California
}

\author{
SORA PARK TANJASIRI, DRPH, MPH, LOLA SABLAN-SANTOS, VINCENT MERRILL, PHD, \\ LOURDES FLORES QUITUGUA, and DARRAH GOO KURATANI, MS \\ Department of Health Science, California State University, Fullerton (SPT, VM, DGK), and the \\ Guam Communications Network, Inc, Long Beach, California (LSS, LFQ)
}

\begin{abstract}
Background-Asian American and Pacific Islander women represent a significant at-risk population for breast cancer, with their mortality rates rising while rates fall for all other racial groups.

Methods-This 3-year study employed a quasi-experimental design to test the influence of an intervention on screening rates among women age 50 years and older in Southern California compared to Northern California.
\end{abstract}

Results-Despite significant exposure of women to the educational elements in Southern California, the intervention did not increase women's knowledge, attitudes, or screening behaviors.

Conclusions-We discuss several study design and implementation limitations that could have influenced the study's results.

Despite significant strides that have been made in the fight against breast cancer in the United States, Asian Americans and Pacific Islanders (AAPIs) continue to experience increased mortality, ${ }^{1}$ signifying the failure of existing community education and intervention campaigns to effectively reach this heterogeneous population. Pacific Islanders comprise a significant at-risk group, ${ }^{2}$ but virtually nothing is known about the ways to control breast cancer, particularly among specific Pacific Islander ethnic subgroups.

Chamorros are indigenous people from Guam and the Commonwealth of the Northern Mariana Islands (CNMI). Since the 17th-century, Guam has been colonized, first by the Spanish and then by the United States. Since 1950, Guam has been an unincorporated US territory with rights of citizenship for all Guamanians. During the US occupation of Guam from 1898-1941, Chamorro women were discouraged from education beyond elementarylevel school. ${ }^{3}$ Subsequently, although most elderly Chamorro women speak English, they often possess little formal education. Despite significant acculturation to Western lifestyles, Chamorros in California maintain extremely close ties to their ethnic communities in Guam as well as on the continent. For instance, whereas in Guam, major decision making and support is provided by the village mayor and community leader, in California, Chamorro Eucharistic Ministers (lay people who volunteer and are trained by the Church to assist the priest in distributing Holy Communion at Mass and to the sick and frail who are homebound) are a very important leadership body on community and health issues.

Address correspondence and reprint requests to: Sora Park Tanjasiri, Associate Professor, Department of Health Science, California State University, Fullerton, PO Box 6870, Fullerton, CA 92834-6870; phone: (714) 278-4592; fax: (714) 278-5317; < stanjasiri@ fullerton.edu>. 
Catholicism has been the prevalent religion on Guam since the Spanish claimed the island in the 17th century. California is home to the largest population of Guamanians or Chamorros outside of Guam and CNMI $(33,849)$, with over half residing in Southern California $(18,471)$. (It should be noted that many data sources do not differentiate between Guamanians, who represent many ethnic populations from Guam and CNMI, and ethnic Chamorros, who are the indigenous people of the region. Thus, we use the term Guamanians only when Chamorro-specific data are not available.) When compared to the state average, Guamanians or Chamorros in California have younger families (32\% have children 0-17 years of age), are poorer ( $10 \%$ below the poverty line), and are less formally educated ( $20 \%$ have less than a high school degree). ${ }^{4}$

Breast cancer is the leading cause of cancer incidence and mortality for women on Guam. ${ }^{5}$ From 1997 to 1999, we conducted the first study of breast cancer and Chamorros in the continental United States, and found that breast cancer represented the most common cancer site for Chamorro women, accounting for $23.5 \%$ of all female Chamorro cancer cases in California. ${ }^{6}$ With regards to early detection, few Chamorro women had ever performed a breast self-examination (BSE; only 37\%), although more had ever had a clinical breast examination (CBE; 93\%) and a mammogram (77\%). When compared with the American Cancer Society's guidelines for regular breast cancer screening, however, rescreening rates were much lower. Only $66 \%$ received a CBE in the past year, $25 \%$ received a mammogram in the past year, and only $27 \%$ performed BSE monthly. Knowledge was significantly associated with screening (women who had correct knowledge about the signs and symptoms of breast cancer were more likely to have been screened), but many misconceptions and myths prevailed among the women. In addition, many Chamorro women associated breast cancer with death and expressed the belief that there is nothing much that can be done if you have the disease.

In this study, we tested the effects of a social network-based intervention on Chamorro women's breast cancer knowledge, beliefs, and screening behaviors. Specifically, we hypothesized that a culturally appropriate and sensitive intervention would significantly increase women's knowledge about, and attitudes toward, early detection (BSE, CBE, and mammography screening) and that the intervention would significantly increase women's appropriate use of BSE and receipt of CBE and mammography screening. In this article, we report on the methods and results of this study, with discussion of these findings on the development and improvement of culturally appropriate health interventions for not only Chamorros but other ethnically specific communities of women across the continental United States.

\section{MATERIALS AND METHODS}

This study involved the active collaboration between Guam Communications Network, Inc (a nonprofit, community-based organization serving Chamorros in Southern California), I Famalao'an (a Chamorro women's civic organization headquartered in Long Beach, CA), the Bay Area Women's Social Club (a nonprofit social organization serving Chamorros in Northern California), and the California State University, Fullerton. We employed a community-based participatory research (CBPR) approach, which brings academic and community researchers together in partnership to conceive, plan, implement, and evaluate efforts that promote community building for health. ${ }^{7}$ In this study, partners from both community and academia collaborated in the entire 3-year effort, which included quarterly meetings of the partnership to inform survey design, pre-testing, data collection, intervention development and implementation, community outreach and education, follow-up data collection, report writing, and dissemination of findings to larger academic and community audiences. 


\section{Theoretical Framework}

The development of our intervention was grounded in the theories of diffusion of innovations, social networks, and community empowerment. Diffusion theory states that new information or knowledge (such as regarding cancer screening) will be passed through defined channels of communication within specific segments of populations. ${ }^{8}$ In communities that are small and defined (such as geographically or ethnically), such diffusion often occurs less through formal channels (because many communities do not have resources like professional newspapers) but through naturally occurring social networks such as between friends, family members, social club members, and women's group volunteers. Social networks help to explain why certain population segments (people who are often called "hard to reach" by researchers who do not understand the culture of communities) do not necessarily adopt a new behavior because diffusion often cannot occur in immigrant, low literacy, non-English-speaking communities without the activation of local social networks. ${ }^{9}$ Such networks can also help women to not only initiate behaviors but also maintain them over time. This is especially crucial for breast cancer screening behaviors, which often require not only individual intent to do the behavior but functional and social support to help women access screening services and any follow-up needs.

\section{Lay Leader Program}

Beginning in 2001, study members designed a culturally tailored breast health intervention that relied on the identification and training of women from the Chamorro community to become lay leaders in the outreach and education of women in their social networks for breast health. The training of community members as health educators represents a wellestablished "gold standard" for community-relevant interventions, relying on trusted community members who bring with them language and cultural skills that enhance intervention appropriateness and relevance. Such an approach has been successfully used in a few AAPI communities, including among Native Hawaiians who served as "navigators" to facilitate discussions among small groups (called "kokua" groups) of women about breast cancer screening and treatment in Waianae. ${ }^{10}$ During the 1 st year of the project, 5 women were recruited and trained to be project lay leaders. The training curriculum was adapted from the Waianae project and included information on breast cancer among Chamorros, breast anatomy, basics of breast cancer risk and symptoms, the proper conduct of BSE, steps involved in CBEs and mammograms, and the basics of cancer treatment (including surgery, radiation, and chemotherapy). The monthly trainings also facilitated discussions about community resources and referrals as well as women's roles in promoting health, including the importance of social networking to promote outreach and education through informal channels of communication. These trainings helped to build a very cohesive and motivated group of lay leaders, who in this 1st year, named the project Guahu I Suruhana ("I am the healer") to signify the important role that Chamorro women play in maintaining not only their families' but also their own health and well-being. At the conclusion of the year-long training, each lay leader was given a jeweled sandal stickpin to symbolize her role as "walking in the community" to promote women's health. They proudly wear this pin to signify the significance of their efforts and the "grounded" way with which they do their work to outreach and educate the community.

Beginning in the middle of 2002, the lay leaders outreached to women (50 years and older) in their social networks to share information about breast health and breast cancer screening. These outreach contacts occurred wherever and whenever the leaders encountered women in naturally occurring gatherings such as at cultural fiestas, birthday parties, and even funeral gatherings. In the Chamorro culture, women get together at social events to help in the kitchen or organize the food preparation and tables. During these events and activities, women tend to converse with one another about their family, community and their health, 
making these settings opportune times for the lay leaders to initiate conversations on breast health and breast cancer screenings. The lay leaders would either begin the conversations (in Chamorro or English) with "I just had my mammogram. How about you?," or "I just saw my doctor and had a complete physical and he/she examined my breasts. What about you?" After initiating the conversations, the lay leaders would introduce breast health, showing how to do a self-breast examination and then stress the importance of early screening. Other times, Chamorro women will identify a lay leader from within a crowd and will make a remark, "Hafa, suruhana (what's up, my healer), I already had my mammogram," at which time the lay leader will take the cue to start a discussion on the importance of annual mammography.

\section{Education and Promotional Materials}

To support the outreach education efforts of the lay leaders, several culturally tailored materials were developed to reinforce messages about breast health and breast exams:

1. A Susu (breast) chart, which was a small card that depicted the steps in breast selfexamination;

2. A basic bingo game, which was adapted with breast health messages to be used as a guide for presentations and as an interactive activity with participants. Each square contained a word or phrase relating to the breast, a medical procedure or early intervention, and each bingo chip had a picture of our project's logo;

3. A "cootie catcher," which started as a flat piece of paper containing messages about the importance of breast cancer screening that, when folded, could be opened and closed to the various messages;

4. A Chamorro breast health brochure, which promoted BSE, CBE, and mammography screening;

5. A Chamorro Kotut Bag, which was a small woven bag that contained culturally recognizable items (a betelnut, mongo bean, grains of rice, and round sea shells) that represented the approximate sizes of breast lumps that could be detected by each screening exam; ${ }^{11}$

6. Pink fabric ribbons that were printed with the words Ma Sodda' Taftaf Satba' I Lina'la ("Early Detection Saves Lives") and given to each woman reached by a lay leader for breast health education;

7. Reminder cards that were given to women each year to encourage them to get their $\mathrm{CBE}$ and mammogram.

In addition, Guam Communications Network also created a breast cancer survivor's quilt, called the Tronkon Niyok, that depicted a coconut tree with the names of the Chamorro breast cancer survivors inscribed on individual hanging coconuts; those who had passed away appeared on coconuts laying on the ground, with a few sprouting new shoots to depict the next generation of Chamorros. This quilt was displayed at various breast health and cultural gatherings as a way to honor survivors and promote positive images of survivorship. As part of the CBPR aspect of the study, women in the control area received a delayed intervention that commenced after the conclusion of all data collection activities (described in the following section).

\section{Evaluation}

To keep track of the lay leader outreach and education activities, each leader kept a journal containing the dates of their activities, names of the women they spoke to, the topics covered, and any relevant observations or insights about the interactions. These journals 
were reviewed periodically by project staff to understand the types of contacts and conversations that were occurring. The contact data in the journals were also used to calculate the total numbers of women reached, average amount of time spent, and range of topics covered.

To evaluate the effects of the Guahu I Surahana program on women's knowledge, attitudes, and behaviors, we employed a quasi-experimental (intervention and control), prospective cohort, pretest-posttest design to measure changes in regular and appropriate BSE, CBE, and mammography screenings among Chamorro women age 50 years and older in Los Angeles and Orange counties of California. Women in Alameda, Solano, and Santa Clara Counties served as controls. To test the effects of the intervention on changes in women's knowledge, attitudes, and behaviors, a self-administered questionnaire was developed that contained the following items: demographics (including age category, natality, marital status, years of education, Chamorro language fluency, and income category); health care access (including health insurance coverage and regular place of health care); breast cancer knowledge, attitudes, and beliefs; and breast cancer screening (including BSE, CBE, and mammography). Surveys were developed in English and then tailored with Chamorro words and phrases inserted throughout the questionnaire. To accommodate the small percentage of women who could not read English, the questionnaire was adapted to be administered in a group setting. Such an approach has been used successfully in other studies, with no significant differences in reliability of self-reported data. ${ }^{12}$

Starting in 2002, approximately 200 women in each community (intervention and control areas) were approached to participate in the study. They were told that they would be participating in 2 questionnaires (a pretest and a 1-year follow-up posttest) and potentially contacted to be involved in educational activities. After obtaining signed informed consent, women were given the pretest questionnaire to complete and return to the researchers. They were also asked detailed contact information on each woman including address, phone number, and the names and telephone numbers of 2 other people who can be contacted in case of loss to follow-up. In return for their participation, each woman received a $\$ 10$ gift certificate for completion of each survey wave. In 2003, each woman was revisited for completion of a posttest questionnaire. This questionnaire contained the same items as at baseline, with a few exceptions. Basic demographic information (age, ethnicity, and language) was omitted, whereas exposure to aspects of the intervention (including lay leaders and educational/promotional materials) was added.

All survey data were entered into an SPSS (SPSS, Inc, Chicago, IL) database at the academic researchers' site. Bivariate comparisons used the student's $t$ test for continuous variables such as age, percent of life spent in the United States, and composite knowledge and attitude scores. Categorical variables were based on both trends in bivariate relationships as well as definitions identified in existing literature. Bivariate comparisons for categorical risk factors used the $\chi^{2}$ test to identify statistically significant associations. McNemar's test was used in cases where matched pairs of subjects with dichotomous outcomes were compared. ${ }^{13}$ All bivariate relationships with a significance level of $<.05$ were included in the multivariate analyses. Variables with a significance level of $<.05$ were considered predictors of screening behavior. All statistical analyses were conducted using SPSS version 13.0. Reflecting the CBPR nature of this study, all findings were reported back to the participating Chamorro communities at the conclusion of the study.

\section{RESULTS}

A total of 404 women (201 respondents in the intervention area of Southern California, 203 respondents in the control area of Northern California) were enrolled at pre-test into the 
study. At posttest, a total of 297 of the women (145 intervention respondents, 152 control respondents) completed a follow-up questionnaire, for a retention rate of $73.5 \%$. Among the women who were lost to follow-up, the main reasons were because they refused or were not interested $(47.5 \%)$, were unable to be located because they moved $(40.5 \%)$, or were deceased (11.9\%). The reasons were not equal between the 2 regions, however; in Southern California, the most common reason was a move, whereas in Northern California, the main reason was refusal or loss of interest in the study. Given the fact that women in Northern California did not receive any education between data collection waves, it is understandable that their level of interest in the study decreased. When we compared the women lost to follow up with those who completed both waves of questionnaires, we found no significant differences with regards to any of the major demographic or health access variables (nativity, Chamorro fluency, marital status, social club membership, age group, health insurance status, years of education, income, mean number of household members, and regular source of medical care).

As shown in Table 1, participating women from both groups at baseline were similar on nearly all demographic characteristics including language proficiency, natality, health insurance coverage, health insurance type, regular place of health care, income, and education. Women in the intervention area were significantly younger and less likely to ever be married than women in the control area.

During the intervention phase of the study, the lay leaders conducted educational outreach to a total of 154 Chamorro women. Due to the social network-based outreach activities of the leaders, at posttest, women in the intervention area were significantly more likely to have been exposed to all the various materials and messages associated with the breast cancer education intervention (see Table 2). Compared to women in the control area, women in the intervention area were significantly more likely to have read about breast cancer in a Chamorro newsletter, seen a Chamorro breast health brochure and Susu chart, received a reminder card about breast screening, talked to Chamorro women about breast health, attended a breast cancer workshop, seen a "cootie catcher" with breast health messages, seen the Tronkon Niyok breast cancer survivor's quilt, and received other cancer information or assistance from staff at Guam Communications Network. Although women in the control area were significantly less likely to have been exposed to these educational elements, nearly half reported receiving a reminder card and $28 \%$ a Susu chart, $21 \%$ reported that they received some form of cancer information or assistance from Guam Communications Network, and $16 \%$ spoke to a Chamorro woman about breast health. Thus, despite the geographic separation between the intervention and control areas, there was a certain amount of diffusion that happened to the women in Northern California.

The comparisons between women in the intervention and control areas at pretest and posttest regarding breast cancer knowledge, attitudes, and beliefs are shown in Tables 3 and 4 . Unfortunately, despite considerable outreach educational efforts by the lay leaders, there were no changes in women's knowledge regarding the risk factors for breast cancer (Table $3)$. Women in the intervention area did not significantly increase their knowledge about either the medically substantiated risk factors (including age, smoking, obesity, age of menstruation, and family history) or the medically unsubstantiated factors (such as breast fondling and implants, hygiene, deodorants, and trauma). The only item to have significant changes was taking illegal drugs; more women in the intervention area at posttest knew that illegal drug use was not a risk for breast cancer. In comparison, more women in the control area knew that breast fondling, lack of hygiene, using deodorants, and taking illegal drugs were not risk factors for breast cancer. 
Similarly, women in the intervention area did not significantly increase any positive attitudes or beliefs toward breast cancer and screening (Table 4), with the exception of the belief that there is something that they can do to prevent breast cancer. At posttest, more women in the intervention area believed that they could do something to prevent breast cancer. In comparison, more women in the control area believed that a mammogram was not only needed if a woman had symptoms, and more women reported that they would undergo breast cancer treatment even if it was painful. Last, there were no significant changes in women's breast cancer screening behaviors (data not shown).

\section{DISCUSSION}

In this article, we have reported on the outcomes of a social network-based intervention to educate Chamorro women about breast health and breast cancer screening. Despite the fact that women in the intervention area were significantly more exposed to all elements of the lay leader-led education, this did not translate into increases in breast health and breast cancer knowledge, positive beliefs and attitudes, nor breast cancer screening. The small number of significant changes in women's knowledge, beliefs, and attitudes could have been obtained by chance, given the large number of significance testing that we performed. We conclude that, although outreach via social networks is a successful strategy to reach Chamorro women, the intensity of the educational message in these naturally occurring encounters was not high enough to result in knowledge, attitudinal, and behavioral changes. Bird et al. ${ }^{14}$ used a similar network strategy in their recruitment of Vietnamese women to attend lay leader-led small group workshops regarding breast and cervical cancer screening. In their design, however, participating women attended between 1 to 3 educational sessions, thereby guaranteeing a minimum amount and concentration of educational intervention delivery. ${ }^{14}$ In our study, a larger proportion of women in the intervention area were exposed to the lower intensity educational components such as receiving a reminder card, seeing a brochure, or reading a newsletter article; fewer women participated in the higher intensity activities such as attending a workshop or survivor forum. Although it is still possible that our social network-based encounters did result in some short-term changes (that were not detected because of the infeasibility of administering pretests and posttests to women during these encounters), it is clear that women did not sustain any changes at the time of the 1year, posttest questionnaire.

The challenges of working with relatively smaller, close-knit ethnic communities were also apparent in the diffusion of educational components to women in the control area of our study. Despite the geographic distance to the Southern California intervention area, women in Northern California were exposed to many aspects of the educational intervention including reminder cards, workshop attendance, and Susu charts. We know that the social networks of Chamorros are very tight and overlapping; indeed, a common saying is that "all Chamorros are related to one another in some way." It is clear that the geographic distance between our 2 areas did not effectively minimize this contamination; indeed, given the close ties of Chamorros to their families in Guam, we question the appropriateness of an experimental or quasi-experimental design for this population. Researchers working with Native Hawaiian populations in Hawaii have reported on a similar type of contamination and have described alternative methods such as focus groups and case studies to document outcomes of community-based participatory research efforts. ${ }^{15,16}$

Last, there were several other limitations of this study that may have impacted our ability to detect differences in women's knowledge, beliefs, attitudes, and behaviors. First, we had a significant loss to follow-up (of 26.5\%) of respondents during the study. Given the need to focus breast cancer screening interventions on women age $40+$ or $50+$ (depending on which organization's screening guidelines are followed), the loss to follow-up will impact a study's 
power to detect statistically significant differences. This is particularly true in relatively smaller ethnic populations, such as Chamorros, for which there are fewer age-appropriate respondents. Second, our data is based on self-report from Chamorro women in each area. Despite our use of a self-administered mode of questionnaire data collection (which we believed to have the lowest social desirability bias), we suspect that women may have reported higher-than-actual behaviors, particularly at pretest, because of their desire to please the questionnaire administrators. Because most women were acquainted with the study staff, future evaluation studies facing this challenge may want to explore alternative data collection modes (such as the Internet) that can be conducted in neutral environments.

Despite our lack of findings regarding the impact on women's breast health and cancer knowledge, beliefs, attitudes, and behaviors, we gained a great deal of learning about how to conduct community-based participatory research efforts in this population. At each stage of the research, when we faced a new challenge (from respondent recruitment and tracking to lay leader training and monitoring), the community and university research team discussed the challenge and developed collaborative strategies that reflected the strengths of both perspectives. Since the conclusion of this study, the community and university partners (in conjunction with 7 other Pacific Islander community organizations) have successfully formed a network to promote community-based education, research, and training for Pacific Islanders throughout Southern California. Called the "Weaving an Islander Network for Cancer Awareness, Research and Training," we are sharing our learnings with other organizations and community populations with the aims of increasing the number and quality of community-driven efforts to decrease the cancer health disparities faced by Chamorros and other Pacific Islanders.

\section{Acknowledgments}

The authors are extremely grateful to the Chamorro communities in both Northern and Southern California for their participation in this study as well as to the team of academic and community researchers who collaborated on the project design, data collection, and analyses: Janet Sanchez, president of I Famalao'an; Maria T. Quinata and Rose F. Pangelinan, past and current presidents of the Bay Area Women's Social Club; and Dr Allan Hubbell and Dr Linton Freeman. Support for this study was provided by the California Breast Cancer Research Program, Grant Numbers 7BB-1900 and 7BB-1901.

\section{References}

1. Edwards BK, Brown ML, Wingo PA, et al. Annual report to the nation on the status of cancer, 1975-2002, featuring population-based trends in cancer treatment. J Natl Cancer Inst. 2005; 97:1407-1427. [PubMed: 16204691]

2. Braun KL, Fong M, Gotay C, Chong CD. Ethnic differences in breast cancer in Hawaii: age, stage, hormone receptor status, and survival. Pac Health Dialog. 2004; 11:146-153. [PubMed: 16281692]

3. Hattori, AP. Colonial Dis-Ease: US Navy Health Policies and hte Chamorros of Guam, 1898-1941. Honolulu: University of Hawaii Press; 2004.

4. Asian Pacific American Legal Center. The Diverse Face of Asians and Pacific Islanders in California. Los Angeles: Asian Pacific American Legal Center; 2005.

5. Tseng C-W, Omphroy G, Cruz L, Naval CL, Haddock RL. Cancer in the Territory of Guam. Pac Health Dialog. 2004; 11:57-63. [PubMed: 16281679]

6. Tanjasiri SP, Sablan-Santos L. Breast cancer screening knowledge and behavior among Chamorro women in southern California. J Womens Health Gend Based Med. 2001; 10:479-485. [PubMed: 11445047]

7. Minkler, MM.; Wallerstein, N. Community-Based Participatory Research for Health. San Francisco: Wiley \& Sons, Inc; 2003.

8. Rogers, EM. Diffusion of Innovations. 5. New York: The Free Press; 1995. 
9. Israel BA, Rounds KA. Social networks and social support: a synthesis for health educators. Adv Health Educ Promot. 1987; 2:331-351.

10. Matsunaga DS, Enos R, Gotay CC, et al. Participatory research in a Native Hawaiian community: the Wai'anae Cancer Research Project. Cancer. 1996; 78(suppl 7):1582-1586. [PubMed: 8839575]

11. Skinner CS, Sykes RK, Monsees BS, Andriole DA, Arfken CL, Fisher EB. Learn, share, and live: breast cancer education for older, urban minority women. Health Educ Behav. 1998; 25:60-78. [PubMed: 9474500]

12. Molitor F, Kravitz RL, To YY, Fink A. Methods in survey research: evidence for the reliability of group administration vs personal interviews. Am J Public Health. 2001; 91:826-827. [PubMed: 11344900]

13. Glantz, SA. Primer of Biostatistics. 5. New York: McGraw-Hill; 2002.

14. Bird JA, McPhee SJ, Ha NT, Le B, Davis T, Jenkins CN. Opening pathways to cancer screening for Vietnamese-American women: lay health workers hold a key. Prev Med. 1998; 27:821-829. [PubMed: 9922064]

15. Gotay CC, Banner RO, Matsunaga DS, et al. Impact of a culturally appropriate intervention on breast and cervical screening among native Hawaiian women. Prev Med. 2000; 31:529-537. [PubMed: 11071833]

16. Fong M, Braun KL, Tsark JU. Improving Native Hawaiian health through community-based participatory research. Calif J Health Promot. 2003; 1(special issue):136-148. 


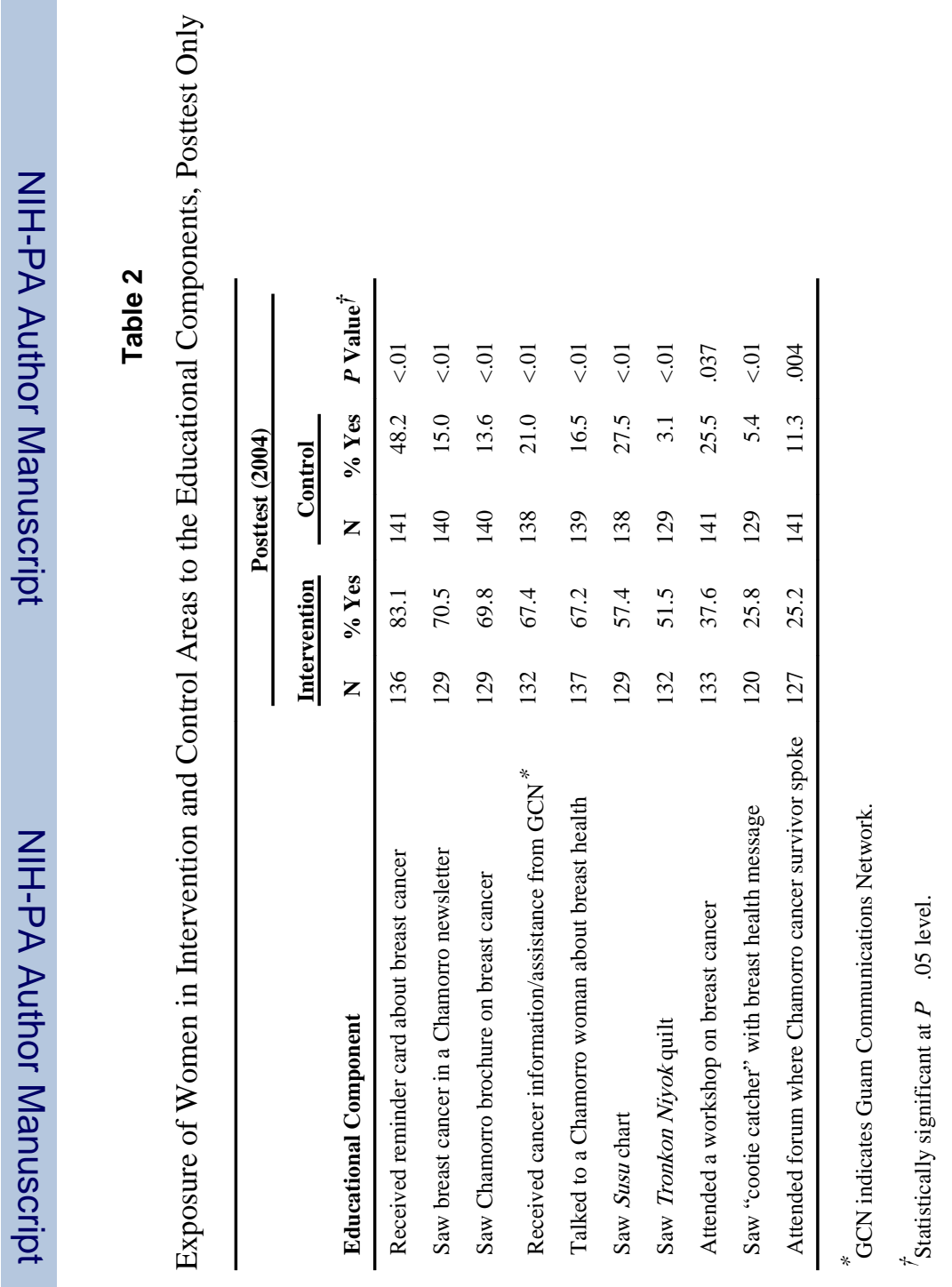

J Cancer Educ. Author manuscript; available in PMC 2013 June 21. 
